\title{
EFFECTS OF BIRTH WEIGHT, SEX AND NEONATAL GLUCOCORTICOID OVEREXPOSURE ON GLUCOSE-INSULIN DYNAMICS IN YOUNG ADULT HORSES.
}

O.A. Valenzuela, J.K. Jellyman, V.L. Allen, N.B. Holdstock*, A.J. Forhead and A.L. Fowden

Departments of Physiology, Development and Neuroscience,

University of Cambridge,

Cambridge, CB2 3EG, United Kingdom.

and

*Department of Veterinary Medicine,

University of Cambridge,

Cambridge, CB3 0ES, United Kingdom

Short title: Factors affecting adult glucose-insulin in adults

Key words: Glucose tolerance, Insulin sensitivity, Programming, Neonatal glucocorticoid overexposure

Address for correspondence: Abigail L. Fowden

Dept. of Physiology, Development and Neuroscience

University of Cambridge

Cambridge

CB2 3EG

UK

Tel: $44(0) 1223333855$

Fax: 44 (0)1223 333840

Email: alf1000@cam.ac.uk 


\begin{abstract}
In several species, adult metabolic phenotype is influenced by the intrauterine environment, often in a sex-linked manner. In horses, there is also a window of susceptibility to programming immediately after birth but whether adult glucose-insulin dynamics are altered by neonatal conditions remains unknown. Thus, this study investigated the effects of birth weight, sex and neonatal glucocorticoid overexposure on glucose-insulin dynamics of young adult horses. For the first 5 days after birth, term foals were treated with saline as a control or ACTH to raise cortisol levels to those of stressed neonates. At 1 and 2 years of age, insulin secretion and sensitivity were measured by exogenous glucose administration and hyperinsulinaemic-euglycamic clamp, respectively. Glucose-stimulated insulin secretion was less in males than females at both ages, although there were no sex-linked differences in glucose tolerance. Insulin sensitivity was greater in females than males at 1 but not 2 years of age. Birthweight was inversely related to the area under the glucose curve and positively correlated to insulin sensitivity at 2 but not 1 years of age. In contrast, neonatal glucocorticoid overexposure induced by ACTH treatment had no effect on whole body glucose tolerance, insulin secretion or insulin sensitivity at either age, although this treatment altered insulin receptor abundance in specific skeletal muscles of the 2 year old horses. These findings show that glucose-insulin dynamics in young adult horses are sexually dimorphic and determined by a combination of genetic and environmental factors acting during early life.
\end{abstract}




\section{INTRODUCTION}

In adult animals including horses, glucose tolerance and insulin sensitivity are influenced by the nutritional, metabolic and endocrine conditions existing at the time of study. ${ }^{1-4}$ There is also increasing evidence from a range of species that conditions during intrauterine development can affect glucose-insulin dynamics of the adult offspring. ${ }^{5-7}$ Low birthweight, in particular, has been associated with glucose intolerance and insulin insensitivity in adult mice, rats, guinea pigs, pigs and sheep as well as in human populations of different ethnicity. 8-14 Indeed, inducing intrauterine growth restriction experimentally by maternal undernutrition, glucocorticoid administration, placental insufficiency or restriction of uterine blood flow causes abnormalities in glucose metabolism and insulin action in the offspring later in postnatal life. ${ }^{5,6,15,16}$ In horses, maternal undernutrition and variations in dietary composition during pregnancy affect insulin secretion and glucose dynamics of newborn and older pre-weaning foals, even when there is no change in birth weight. ${ }^{17-19}$ Similarly, dexamethasone treatment of mares during late pregnancy alters arginine-stimulated insulin secretion in their foals 12 weeks after birth relative to controls of the same birth weight. ${ }^{20}$ Collectively, the experimental and epidemiological studies have led to the concept that postnatal metabolic phenotype can be programmed in utero, particularly by environmental conditions suboptimal for normal fetal development.

Recent studies in horses have suggested that there is also a window of susceptibility to metabolic and endocrine programming in the early neonatal period. ${ }^{15,16}$ In contrast to other precocious species, the horse matures late in gestation and is born with several of its key tissues still not terminally differentiated. ${ }^{16}$ Indeed, glucocorticoid overexposure of the foal in the days immediately after birth alters its subsequent endocrine and metabolic profile. ${ }^{21,22}$ For instance, there are changes in insulin secretion in response to both glucose and arginine in the foal up to 12-14 weeks after the period of glucocorticoid overexposure. ${ }^{21}$ In addition, in 2 week old foals, pancreatic $\beta$ cell sensitivity to glucose differs with sex with greater insulin secretion in females than males. ${ }^{23}$ However, whether the differences in glucose-insulin dynamics seen with sex and neonatal glucocorticoid exposure in pre-weaning foals persist into later life remains unknown. This study, therefore, examined glucose tolerance, insulin secretion and insulin sensitivity of young adult horses with respect to sex, birth weight and neonatal glucocorticoid overexposure. 


\section{MATERIALS AND METHODS}

\section{Animals}

Nineteen ponies were used in the study. They were born spontaneously at full term (approx. 330 days of gestation) and were treated intramuscularly with equine tetanus antitoxin shortly after birth (1000 IU; Tetanus Antitoxin Intervet Ltd, UK). They were housed with their mothers in individual stables for 7 days after birth and then at grazing during the day until they were weaned at 5-6 months. Thereafter, until catheterization, they were kept at grazing during the day and housed in covered yards at night with access to hay and water. Body condition score was maintained at moderate from weaning until the end of the protocol. ${ }^{24,25}$ Colts and fillies occupied separate paddocks and yards from 9 months of age. All animals were wormed and had their hooves trimmed regularly. They were also weighed regularly to calculate fractional growth rates $(\mathrm{g} / \mathrm{kg}$ birth weight/week) up to the experiments at 1 and 2 years of age.

\section{Experimental Procedures}

All procedures were carried out under the Animal (Scientific Procedures) Act 1986 of the UK Government after ethical permission from the University of Cambridge.

\section{Foals}

Foals were injected intramuscularly with either long-acting $\mathrm{ACTH}_{1-24}(0.125 \mathrm{mg}, \mathrm{n}=9,4$ males and 5 females, Depot Synacthen, Alliance Pharmaceuticals Ltd, Wiltshire, UK) or saline $(0.9 \% \mathrm{NaCl}, \mathrm{n}=10,4$ males and 6 females $)$ twice daily at between 08.00 and $09.00 \mathrm{~h}$ and between $16.30 \mathrm{~h}$ and $17.00 \mathrm{~h}$ for 5 days after birth beginning on the first day of postnatal life. Blood samples were taken daily from the jugular vein immediately before the first daily injection from day 1 to day 6 to measure plasma cortisol concentrations. The ACTH dose was designed to increase endogenous cortisol concentrations to the levels seen in premature or ill newborn foals ${ }^{26,27}$ and resulted in plasma cortisol concentrations that were higher in ACTH than saline treated foals over the 5 days of treatment (Saline, $20.4 \pm 1.8 \mathrm{ng} / \mathrm{ml}, \mathrm{n}=10$; ACTH, $207.2 \pm 49.3 \mathrm{ng} / \mathrm{ml}, \mathrm{n}=9, \mathrm{P}=0.01){ }^{21}$ Foals were assigned to either ACTH or saline treatment alternately in the order in which they were born on the basis of their sex to ensure an even sex distribution between the two treatment groups. 


\section{Adults}

Surgical procedures: At 10-13 months (yearling or 1 year old group) and again between 2334 months (2 year old group), the ACTH and saline treated ponies were fasted over night before catheterisation under general anaesthesia with positive pressure ventilation using strict aseptic procedures as described in detail previously. ${ }^{28,29}$ At both ages, catheters were inserted into the caudal vena cava and dorsal aorta via the circumflex artery and vein. ${ }^{28}$ The catheters were filled with heparinised saline (100 IU heparin $/ \mathrm{ml}$ in $0.9 \% \mathrm{w} / \mathrm{v} \mathrm{NaCl}$ ), exteriorized via a stab wound in the flank and housed in a bag sutured to the side of the horse. At the end of surgery, a long stay 16-gauge catheter was placed in a jugular vein (Milacath $^{\circledR}$, Mila International Inc., Erlanger, KY, USA) and the horse was given antibiotics ( $1 \mathrm{ml} / 25 \mathrm{~kg}$ i.m, procaine penicillin BP $200 \mathrm{mg}$ and dihydrostreptomycin sulphate BP (vet) $250 \mathrm{mg}$; Pencillin \& Strep; Norbrook Laboratories Ltd, UK) and an anti-inflammatory $(1.1 \mathrm{mg} / \mathrm{kg}$, flunixin meglumine; Finadyne 50mg, Shering-Plough Ltd, Welwyn Garden City, UK) intramuscularly. Postoperatively, the horses were housed in individual pens in sight of other horses with access to hay and water ad libitum. Catheters were flushed daily with heparinised saline (100 IU heparin $/ \mathrm{ml}$ in $0.9 \% \mathrm{w} / \mathrm{v} \mathrm{NaCl}$ ) until the onset of physiological assessments. At the end of the experimental period as yearlings, the catheters were removed under sedation (Xylazine: $1.1 \mathrm{mg} / \mathrm{kg}$ i.v Rompun, Bayer Ltd, UK) and the ponies re-catheterised on the contralateral side at 2 years of age.

Glucose tolerance tests: Insulin secretion was assessed using a glucose tolerance test. At least 5-7 days after surgery following an overnight fast, glucose was infused intravenously over 5 $\min (0.25 \mathrm{~g} / \mathrm{kg}, 40 \%$ dextrose; Arnolds, Harlescott, Shrewsbury, UK) via the venous catheter and arterial blood samples $(5 \mathrm{ml})$ were collected at $-30,-15$, and 0 min (immediately before) and 5, 15, 30, 45, 60, 90, and $120 \mathrm{~min}$ after glucose administration. The blood samples were placed into tubes containing heparin or EDTA and centrifuged immediately at $4{ }^{\circ} \mathrm{C}$ before storage of the plasma at $-20^{\circ} \mathrm{C}$ until measurement of plasma glucose and insulin concentrations.

Insulin sensitivity tests: Between 7-10 days after the glucose tolerance test, insulin sensitivity was assessed using a hyperinsulinaemic-euglycaemic clamp (HEC) following an overnight fast. After collecting basal blood samples $(5 \mathrm{ml})$ from the arterial catheter at 10 min intervals for 40-60 min, insulin was infused continuously via the caudal vena cava catheter at a rate of $5 \mathrm{mU} / \mathrm{kg} / \mathrm{min}$ (Insuvet ${ }^{\circledR}$ Neural, Shoering-Plough Animal Health, Welwyn Garden City, UK 
in Year 1 or Actrapid Actrapid® HM, Insulin Human biosynthetic 100 IU/ml, Novo Nordisk Pharma, Denmark in Year 2) using a peristaltic pump. After insulin infusion for $10 \mathrm{~min}$, glucose (40\% dextrose, Arnolds, Harlescott, Shrewsbury, Shropshire, UK) was infused at a variable rate using a precision infusion pump to maintain glucose levels at basal values. Once steady state was established after about 2-5h of insulin and glucose infusion, a second series of arterial blood samples $(5 \mathrm{ml})$ were collected at $10 \mathrm{~min}$ intervals for $40 \mathrm{~min}$ for the measurement of the concentrations of blood glucose and plasma insulin. After the clamped period, the insulin and glucose infusion was stopped and the horses were fed with $500 \mathrm{~g}$ concentrates (Horse Stud Mix; Moulton's Feed Supplies, Lincolnshire, UK) plus hay ad libitum.

At the end of the experimental studies as 2 year olds, the catheters were removed under sedation as at 1 year and the animals were either rehomed $(n=10)$ after discharge from the Animal (Scientific Procedures) Act 1986 or euthanized $(n=9)$ by intravenous administration of a lethal dose of anaesthetic (pentobarbitone sodium; $200 \mathrm{mg} / \mathrm{kg}$, Pentoject, Animal Care Ltd, Commond Road, Dunnington, York, UK). For the current study, samples of liver and skeletal muscles (biceps, soleus, gastrocnemius and semitendinosus) were collected into liquid nitrogen and stored at $-80^{\circ} \mathrm{C}$ until required for analyses. These and other tissues were also collected for teaching and other research studies.

\section{Biochemical analyses}

\section{Metabolite and hormone concentrations:}

Blood and plasma glucose concentrations were measured using an automated analyzer (Yellow Springs 2300 Stat Plus Glucose/Lactate Analyzer; YSI Ltd., Farnborough, UK). Plasma insulin concentrations during the glucose tolerance test and the basal samples from the hyperinsulinaemic-euglycaemic clamp were measured using a commercially available, equine specific enzyme linked immunosorbent assay (ELISA) kit (Mercodia AB, Uppsala, Sweden), validated for use with equine plasma. ${ }^{30,31}$ The mean intra-assay coefficient of variation was $3.4 \%$ while the inter-assay coefficient of variation was $13 \%$. The minimum detectable level of equine insulin was $0.01 \mu \mathrm{g} / \mathrm{l}$. Insulin concentrations during the clamp period were measured after dilution using commercially available human and bovine ELISA kits as appropriate (Mercodia AB, Uppsala, Sweden). The clamped insulin concentrations 
were measured in a single assay at each age. For the human and bovine insulin assays, the minimum detectable of insulin was $0.04 \mu \mathrm{g} / 1$ and $0.02 \mu \mathrm{g} / 1$ while the intra-assay coefficient of variation was $3.4 \%$ and $3.8 \%$, respectively.

\section{Tissue insulin receptor abundance}

Protein was extracted from liver and the four skeletal muscles and the protein concentration in the supernatant was determined using a bicinchoninic acid assay (BCA kit; Pierce, Rockford, IL). Western Blotting was performed as described previously ${ }^{32}$ using a primary antibody to the insulin receptor (InsR, subunit $\beta$ (Insulin R $\beta$ (C-19): (1:200; sc-711, Santa Cruz Biotechnology, inc, Delawere Avenue, Santa Cruz, CA, USA) and to $\beta$-actin $(1: 10,000$; sc-47778, Santa Cruz Biotechnology, inc, Delawere Avenue, Santa Cruz, CA, USA) to evaluate protein loading. Horseradish peroxidase-conjugated secondary antibodies to the host species were used as appropriate (1:5,000-1:10,000; $\mathrm{ECL}^{\mathrm{TM}}$ Anti-rabbit IgG and $\mathrm{ECL}^{\mathrm{TM}}$ Anti-mouse IgG; GE Healthcare Life Sciences, Little Chalfont, Bucks, UK). Protein abundance was detected using enhanced chemiluminescence reaction (ECL plus kit, Amersham Hiperfilm Bioscience, UK) and X-ray film (Fuji FPM100A processor) and analysed using the ImageJ program (ImageJ, Software, National Institute of Health, Bethesda, MD; http://rsb.info.nih.gov/ij). The depicted bands had the expected molecular weights.

\section{Calculations}

Glucose tolerance test: Relative insulin secretion (RIS) was calculated as area under the insulin curve (AUCI) divided by area under the glucose curve (AUCG).

$$
\mathrm{RIS}=\frac{\text { AUCI (ng/l/min })}{\operatorname{AUCG}(\mathrm{mmol} / \mathrm{l} / \mathrm{min})}
$$

Hyperinsulinsemic-euglycaemic clamp (HEC): As the glucose concentration is not maintained perfectly constant during the clamp, a space correction (SC) is made to account for the glucose that has been added or removed from the glucose space other than by metabolism. ${ }^{33}$ No correction was made for urinary losses of glucose, irrespective of whether the animals urinated or not during the course of the experiments.

The SC ( $\mu \mathrm{mol} / \mathrm{kg} / \mathrm{min})$ was calculated from the equation: 


$$
\mathrm{SC}=\left(\mathrm{G}_{2}-\mathrm{G}_{1}\right) \times(0.19 \mathrm{btw}) /(\mathrm{T} \times \mathrm{bwt})^{33}
$$

Where $G_{2}$ and $G_{1}$ are glucose concentration at the beginning and end of each interval of sampling, $\mathrm{T}$ is the time interval (10 minutes), btw is body weight in $\mathrm{kg}$, and the term $(0.19 \mathrm{x}$ body weight) is the glucose space expressed in litres (1). The net steady state glucose infusion rate (Net GIR) ( $\mu \mathrm{mol} / \mathrm{kg} / \mathrm{min}$ ) was calculated by use of the following equation:

Net steady state GIR $=(\mathrm{GIR}-\mathrm{SC})$

where GIR is the glucose infusion rate $(\mu \mathrm{mol} / \mathrm{kg} / \mathrm{min})$ averaged over the clamp period and SC is the space correction. Insulin sensitivity $\left(\mu \mathrm{mol} / \mathrm{min}^{\prime} \mathrm{kg}^{\prime} \mu \mathrm{g} / \mathrm{l}\right)$ was calculated as the net steady-state glucose infusion rate divided by the steady-state plasma insulin concentration during the clamp period. ${ }^{34}$

IS $=\quad$ Net steady-state glucose infusion rate $(\mu \mathrm{mol} / \mathrm{kg} / \mathrm{min})$

Steady-state plasma insulin concentration $\mu \mathrm{g} / 1$

The steady-state plasma insulin concentration was calculated as the average of insulin concentrations during the clamp period.

\section{Statistical Analyses}

All results are expressed as means \pm S.E.M. Plasma glucose and insulin concentrations during each experimental period were analysed using two-way analysis of variance (ANOVA) with repeated measures plus Tukey post hoc test, as appropriate. The area under the curve for glucose (AUCG) and insulin responses (AUCI) were calculated as the integrated plasma concentration after administration of glucose from 0 to $120 \mathrm{~min}$ above the baseline concentration at $0 \mathrm{~min}$ for all positive values. Statistical comparisons between groups were made using two ANOVA (treatment and time or treatment and sex) followed by Tukey post hoc test. Data were normalised by log transformation where required. The data for growth rate and from the HEC experiments at each age were analysed using two-way ANOVA using treatment and sex of the ponies as factors. Linear regression analyses were used to assess the relationships between birth weight, growth rate and AUCG and insulin sensitivity. Statistical analyses were performed using Sigma-Stat (Statistical Software version 2.0, San Jose, USA). For all statistical tests, significance was accepted at $\mathrm{P}<0.05$. 


\section{RESULTS}

\section{Biometry}

Birth weight did not differ between female and male foals ( $\mathrm{P}>0.05$, Table 1). There was also no difference in the body weight of the fillies and colts at 1 and 2 years of age $(\mathrm{P}>0.05$, Table 1). Neonatal treatment had no effect on body weight at either age ( $\mathrm{P}>0.05$, Table 1$)$. In addition, there were no significant differences in the fractional growth rate with sex or neonatal treatment during the period of study $(\mathrm{P}>0.05$, Table 1$)$.

\section{Glucose tolerance}

At 1 and 2 years of age, there were no differences in the basal fasting concentrations of plasma glucose and insulin with neonatal treatment or sex of the animals $(\mathrm{P}>0.05$, Table 1$)$. At both ages, the increment in plasma glucose with respect to time and the maximal increment in plasma glucose were similar in males and females and did not differ with neonatal treatment $(\mathrm{P}>0.05$, Table 1, Figure 1A). Similarly, the AUCG was unaffected by either sex or neonatal treatment of the animals, irrespective of their age (Figure 1B). The increment in plasma insulin with respect to time was also unaffected by neonatal treatment $(\mathrm{P}>0.05$, Figure 1C). However, the increment in plasma insulin from basal values was greater in females than males from 60 min to 120 min after glucose administration in the yearlings and from $30 \mathrm{~min}$ to $120 \mathrm{~min}$ in the 2 year olds $(\mathrm{P}<0.02$, Figure $1 \mathrm{C})$. Similarly, the the maximum concentration of plasma insulin achieved during the 120 min period after glucose administration was significantly higher in females than males at both ages $(\mathrm{P}<0.04$, Table 1). Consequently, the AUCI was significantly greater in females than males at both ages studied $(\mathrm{P}<0.02$, Figure 1D). The relative insulin secretion were significantly greater in females than males at 2 but not 1 years of age $(\mathrm{P}<0.04$, Table 1$)$ and was unaffected by neonatal treatment at both ages $(\mathrm{P}>0.05$, Table 1$)$. When the two sexes were analysed separately, there were no changes in the increments of glucose and insulin, the AUCG and AUCI or in RI between 1 and 2 years of age in either sex ( $P>0.05$, two-way ANOVA, all cases)

\section{Insulin sensitivity}

Basal blood glucose concentrations did not vary with sex or neonatal treatment at either age $(\mathrm{P}>0.05$, all cases; mean values: 1 year, $4.49 \pm 0.17 \mathrm{mmol} / \mathrm{l}, \mathrm{n}=13 ; 2$ years, $4.70 \pm 0.19$ $\mathrm{mmol} / \mathrm{l}, \mathrm{n}=17$ ) and were clamped at these basal euglycaemic levels by $2-5 \mathrm{~h}$ after beginning 
the insulin infusion. At this time, insulin concentrations were supra-physiological and did not vary with neonatal treatment or sex of the animal at either 1 or 2 years of age $(\mathrm{P}>0.05$, all cases: mean clamped values; 1 year, $52.5 \pm 5.1 \mu \mathrm{g} / 1, \mathrm{n}=13,2$ years, $59.6 \pm 5.6 \mu \mathrm{g} / 1, \mathrm{n}=17)$. At both ages, the effectiveness of insulin in stimulating tissue glucose uptake was unaffected by neonatal treatment, whether measured as GIR or insulin sensitivity $(\mathrm{P}>0.05$, Figure 2$)$. Females had a greater GIR and insulin sensitivity than males as yearlings but not as 2 years olds (Figure 2). When the data from the two treatment groups were combined and analysed by two-way ANOVA with respect to age and sex of the animals, there was an interaction between these two factors in determining insulin sensitivity with a decline in insulin sensitivity with increasing age in females $(\mathrm{P}<0.001, \mathrm{n}=9)$ but not in males $(\mathrm{P}>0.05, \mathrm{n}=8)$. Insulin receptor abundance in the liver and selected skeletal muscles was unaffected by sex in a subset of the animals at 2 years of age ( $\mathrm{P}>0.05$, two-way ANOVA, all cases, Figure 3 ). However, skeletal muscle InsR abundance was influenced by neonatal treatment in a muscle specific manner with increased abundance in the soleus and gastrocnemius muscles and decreased abundance in the semitendinosus muscle of animals treated neonatally with ACTH compared to those receiving saline (Figure 3B-D). There was no apparent effect of neonatal treatment on InsR abundance in the liver or biceps muscle (Figure $3 \mathrm{~A} \& \mathrm{E}$ ).

\section{Relationships to birth weight and postnatal growth rates}

When all data were combined irrespective of sex or treatment at each of the two ages, there was no relationship between birthweight (BW) and either AUCG or insulin sensitivity in the yearlings ( $\mathrm{P}>0.05$, both cases). In contrast, at 2 years of age, AUCG was inversely related to the birthweight (Figure 4A, AUCG $=982-13.0 \mathrm{BW}, \mathrm{n}=18, \mathrm{r}=-0.487, \mathrm{P}=0.04$ ) while, conversely, insulin sensitivity was positively correlated to birth weight of the foals (Figure $4 \mathrm{~B}, \mathrm{IS}=-159+15.6 \mathrm{BW}, \mathrm{n}=17, \mathrm{r}=0.658, \mathrm{P}=0.04)$. There were no relationships between the fractional growth rate until the age at study $(\mathrm{g} / \mathrm{kg} /$ day) and either AUCG or insulin sensitivity at 1 and 2 years of age $(\mathrm{P}>0.05$, all cases). Nor was there any relationship between birthweight and AUCI at 1 and 2 years of age when the data from the two sexes were analysed separately ( $\mathrm{P}>0.05$, all cases). 


\section{DISCUSSION}

The results demonstrate that sex, birth weight and neonatal glucocorticoid overexposure are all significant influences on the glucose-insulin dynamics of young adult horses. Insulin secretion in response to glucose was sex-linked at both ages studied as was insulin sensitivity in the yearlings. Birth weight was related to the action of insulin in the 2 year olds, irrespective of whether insulin effectiveness was measured as area under the AUCG in the glucose tolerance test or more directly as insulin sensitivity using the hyperinsulinaemiceuglycaemic clamp technique. In contrast, neonatal glucocorticoid overexposure appeared to have little effect on glucose tolerance, insulin secretion or insulin sensitivity of the horses at either age studied, although it did affect InsR abundance of specific skeletal muscles at 2 years in a manner independent of the sex of the animal. The current findings together with previous studies $^{21-23}$ suggest that sex of the animal and environmental factors during fetal and early neonatal life are likely to be important in determining postnatal metabolic and endocrine phenotype in horses as occurs in other species. $5,6,15,16$

Insulin secretion in response to glucose administration was greater in females than males at both 1 and 2 years, consistent with findings in newborn foals at 2 weeks of age. ${ }^{23}$ Sex-linked differences in glucose-stimulated insulin release have also been reported in rats, guinea pigs and sheep postnatally, particularly when there is a suboptimal environment during their intrauterine development. ${ }^{10,35-40}$ However, in these earlier studies, it was generally the males rather than the females that had a greater insulin response to exogenous glucose administration. In part, this was due to sex-linked changes in pancreatic $\beta$ cell mass and/or alterations in the intracellular pathways of insulin secretion. ${ }^{41-43}$ The mechanisms responsible for the differences in glucose-stimulated insulin secretion between the sexes in the horses in the current study are unknown.

Despite the difference in insulin secretion between the male and female horses, glucose dynamics and AUCG were unaffected by the sex of the ponies at both ages studied. This suggests that insulin sensitivity was greater in males than females. However, direct measurement of insulin sensitivity using hyperinsulinaemic-euglycaemic clamps showed that the females were the more insulin sensitive sex as yearlings with no difference between the sexes at 2 years of age. Sex-linked differences in adult insulin sensitivity have been observed 
previously in rats, guinea pigs, sheep and humans and are often related to differences in adiposity. ${ }^{10,11,37,39,44,45}$ Body condition score was maintained at moderate in all animals in the current study so changes in adiposity are unlikely to account for the sex-linked differences in insulin sensitivity seen in the yearlings. In a subset of the current 2 year old horses, there were also no apparent sex-linked differences in InsR abundance in the liver or skeletal muscles, the main sites of insulin action. Consequently, the paradoxical findings of no sexlinked difference in AUCG but increased insulin secretion and sensitivity in the female yearlings relative to the males indicates that any increased insulin-stimulated glucose uptake during the glucose tolerance test is probably balanced by an equal and opposite decrease in insulin independent glucose disposal in the females. Conversely, in the older animals, there were no differences in insulin sensitivity or glucose tolerance between the sexes, despite the smaller insulin response to glucose administration in the males, which suggests insulin dependent glucose uptake may be less while insulin independent glucose disposal may be greater in males than females during glucose administration at 2 years of age. There may, therefore, be sexual dimorphism in the tissue expression and relative abundance of the various glucose transporters (GLUTs) in equine tissues, which differ with age. Certainly, in other species, there are sex-linked differences in tissue abundance of both the insulin sensitive GLUT isoform, GLUT4, and the insulin-insensitive isoforms, GLUT1 and GLUT2 in the adult animal, particularly when it has experienced adverse conditions during intrauterine development. ${ }^{46-49}$

In the current study, the weight specific rates of glucose infusion during the clamp were within the range of values reported previously for adult horses of several different breeds including ponies. ${ }^{33,50-54}$ Collectively, these studies suggest that insulin sensitivity may vary between breeds with a trend towards greater insulin resistance in ponies than more athletic breeds of horse. They also indicate that insulin sensitivity may decline with age as GIR values tended to be lower in horses older than 12 years than in younger animals of the same breed. ${ }^{17,52,54}$ Certainly, in the current study, insulin sensitivity decreased between 1 and 2 years of age in the females, although not the males. Since insulin sensitivity is affected by puberty in other species ${ }^{55}$, this may reflect, in part, the tendency for an earlier onset of puberty in fillies than colts. ${ }^{56}$

The current finding that birth weight was inversely correlated to AUCG and positively related to insulin sensitivity in the 2 years old horses is consistent with previous studies of natural 
and experimentally induced variations in birth weight in other species. ${ }^{5,6,15,16}$ Adult insulin sensitivity is known to be less in smaller than larger littermates in pigs and guinea pigs. ${ }^{10,57,58}$ Similarly, in Standardbred horses, insulin sensitivity is less in pre-weaning foals that were growth restricted than in those growth enhanced by embryo transfer into smaller and larger breeds of mares, respectively. ${ }^{59}$ In addition, resistance to the effects of insulin is greater in adult rats of low birth weight, irrespective of whether intrauterine growth restriction was induced by uterine artery ligation, maternal glucocorticoid administration or restriction of dietary protein or calories intake. ${ }^{13,32,35,60}$ However, since insulin is an important regulator of fetal growth in species with relatively long gestational periods like the sheep and horse ${ }^{16}$, the relationship between adult insulin sensitivity and birth weight across the normal range may not be due to intrauterine programming but rather reflect an inherent, genetically determined insulin sensitivity tracking from fetal to early adult life. The absence of this relationship in the yearlings may again be the consequence of the changes in insulin sensitivity associated with puberty. ${ }^{55,56}$

In the current study, neonatal glucocorticoid overexposure induced by ACTH treatment had little effect on adult insulin secretion or whole body insulin sensitivity of the young adult horses. In contrast, this treatment reduced peak insulin concentrations in response to glucose administration in 2 and 12 week old foals and altered functioning of the hypothalamicpituitary-adrenal (HPA) axis in both the males and females as yearlings and 2 year olds. ${ }^{21,22}$ At 2 years of age, neonatal glucocorticoid overexposure affected InsR expression in skeletal muscles differentially with increases, deceases and unaltered abundance depending on the specific muscle studied, which may reflect, in part, the differing fibre composition of the muscles. While these changes in InsR abundance might alter insulin sensitivity of the individual muscles, they appeared to have no net effect on insulin-dependent glucose utilisation by the animal as a whole.

In summary, insulin-glucose dynamics in the young adult horse varied with birth weight and sex in line with previous findings in newborn and older pre-weaning foals. This suggests that these metabolic characteristics are determined early in life and track into adulthood. However, whether this reflects the genotype of the individual or intrauterine programming of its metabolic phenotype remains unclear. In comparison, neonatal glucocorticoid overexposure appeared to have little effect on glucose-insulin dynamics of young adult horse as a whole, although insulin sensitivity of its individual skeletal muscles may have been 
altered by the ACTH treatment. Taken together, the current and previous findings indicate that glucose metabolism of the young adult horse may be less sensitive to glucocorticoid programming during early neonatal life than functioning of its HPA axis. ${ }^{22}$ In other species, abnormalities in glucose metabolism and insulin sensitivity programmed in utero become more evident with increasing postnatal age and adiposity ${ }^{6,61}$ but whether this occurs in horses overexposed to glucocorticoids neonatally remains to be determined. Further studies are also required to identify the cellular and molecular basis of the differences in insulin-glucose dynamics linked to the sex and birth weight of the young adult horses.

\section{ACKNOWLEDGEMENTS}

We would like to thank the staff of the University Biofacilities Service for their care of the animals. We are also grateful to the Horserace Betting Levy Board for their financial support. 


\section{REFERENCES}

1. Scheen AJ, Van Cauter E. The roles of time of day and sleep quality in modulating glucose regulation: clinical implications. Horm Res. 1998; 49, 191-201.

2. Bulló M, Cózar-Torrell P, Salas-Salvadó J. Dietary regulation of glucose metabolism in metabolic syndrome. Curr Vasc Pharmacol. 2013; 11, 928-945.

3. Ralston SL. Insulin and glucose metabolism. Vet Clin North Am Equine Pract. 2002; $18,295-304$.

4. Firshman AM, Valberg SJ. Factors affecting clinical assessment of insulin sensitivity in horses. Equine Vet J. 2007; 39, 567-575.

5. McMillen IC, Robinson JS. Developmental origins of metabolic syndrome: prediction, plasticity and programming. Physiol Rev. 2005; 85, 571-633.

6. Ong TP, Ozanne SE Developmental programming of Type 2 diabetes: early nutrition and epigenetic mechanisms. Curr Opin Clin Nutr Metab Care. 2015; 18, 354-360.

7. Gonzalez-Bulnes A, Astiz S, Ovilo C et al. Developmental origins of health and disease in swine: implications for animal production and biomedical research. Theriogenology. 2016; 86, 110-119.

8. Poore KR, Fowden, AL The effect of birth weight on glucose tolerance in pigs at 3 and 12 months of age. Diabetologia. 2002; 45, 1247-1254.

9. Hales CN, Marker DJ, Clark PM et al. Fetal and infant growth and impaired glucose tolerance at age 64. BMJ 1991; 303, 1019-1022.

10. Kind KL, Clifton PM, Grant PA, et al. Effect of maternal feed restriction during pregnancy on glucose tolerance in the adult guinea pig. Am J Physiol Regul Integr Comp Physiol. 2003; 284, R140-152. 
11. Lui H, Schulz CG, De Blasio MJ, et al. Effect of placental restriction and neonatal exendin-4 treatment on postnatal growth, adult body composition and in vivo glucose metabolism in the sheep. Am J Physiol Endocrinol Metab. 2015; 309, E589-E600.

12. Clarke L, Firth K, Heasman L, et al. Influence of relative size at birth on growth and glucose homeostasis in twin lambs during juvenile life. Reprod Fertil Dev. 2000; 12, 69-73.

13. Jansson T, Lambert GW. Effect of intrauterine growth restriction on blood pressure, glucose tolerance and sympathetic nervous system activity in the rate at 3-4 months of age. $J$ Hypertens. 1999; 17, 1239-1248.

14. Wang J, Tang H, Wang H, et al. The structural alteration of gut microbiota in lowbirth-weight mice undergoing accelerated postnatal growth. Sci Rep. 2016; 6, 27780.

15. Coverdale JA, Hammer CJ, Walter KW. Nutritional programming and the impact on mare and foal performance. J Anim Sci. 2015; 93, 3261-3267.

16. Fowden AL, Jellyman JK, Valenzuela OA, Forhead AJ. Nutritional programming of intrauterine development: a concept applicable to the horse? J. Equine Vet Sci. 2013; 33, 295-304.

17. George LA, Staniar WB, Trieber KH, Harris PA, Geor RJ. Insulin sensitivity and glucose dynamics during pre-weaning foal development and in response to maternal dietary composition. Domest Anim Endocrinol. 2009; 37, 23-29.

18. Ousey JC, Fowden AL, Wilsher S, Allen WR. The effects of maternal health and body condition on the endocrine responses of neonatal foals. Equine Vet J. 2008; 40, 673-679.

19. Peugnet P, Robies M, Medoza L, et al. Effects of moderate amounts of barley in late pregnancy on growth, glucose metabolism and osteoarticular status of pre-weaning horses. PLoS One. 2015; 10, e0122596. 
20. Valenzuela OA, Jellyman, JK, Allen VL, Holdstock NB, Fowden, A.L. Effects of maternal dexamethasone treatment on pancreatic $\beta$ cell function in the pregnant mare and postnatal foal. Equine Vet. J. 2016; DOI: 10.1111/evj.12560.

21. Jellyman JK, Allen VL, Holdstock NB, Fowden AL. Glucocorticoid over-exposure in neonatal life alters pancreatic $\beta$ cell function in newborn foals. $J$ Anim Sci. 2013; 91, 104110.

22. Jellyman JK, Valenzuela OA, Allen VL, et al. Neonatal glucocorticoid overexposure programmes pituitary-adrenal function in ponies. Domest Anim Endocrinol. 2015; 50, 45-49.

23. Jellyman JK, Valenzuela OA, Allen VL, Holdstock NB, Fowden AL. Sex-associated differences in pancreatic $\beta$ cell function in healthy pre-weaning foals. Equine Vet J. 2014; 46, $722-728$.

24. Carroll CR, Huntingdon PJ. Body condition scoring and weight estimation of horses. Equine Vet J. 1988; 20, 41-45.

25. Hennecke DR, Potter GD, Kreider JV, Yates BF. Relationship between condition score, physical measurements and body fat percentage in mares. Equine Vet J. 1983; 16, 371372.

26. Panzini SM, Villani A, McGladdery A, et al. Concentrations of 15-ketodihydroPGF2alpha, cortisol and progesterone in the plasma of healthy and pathological foals. Theriogenology 2009; 72, 1032-1040.

27. Silver M, Ousey JC, Dudan FE et al. Studies on Equine prematurity2: Postnatal adrenocortical activity in relation to plasma adenocorticotrophic hormones and catecholamine levels in term and premature foals. Equine Vet J. 1984; 16, 278-286.

28. Taylor PM, White KL, Fowden AL, Giussani DA, Bloomfield M, Sear JW. Propofol anaesthesia for surgery in late gestation pony mares. Vet Anaes Anal. 2001; 28, 177-187. 
29. deVries M, Taylor PM, Troughton G, Fowden AL, Sear J. Real time monitoring of propofol blood concentration in ponies anaesthetized with propofol and ketamine. J. Vet. Pharm. Thera. 200336 258-266.

30. Borer-Weir KE, Bailey SR, Menzies-Gow, Harris PA, Elliot J Evaluation of a commercially available radioimmunoassay and species specific ELISAs for measurement of high concentrations of insulin in equine serum. Am J Vet Res. 2012; 73, 1596-1602.

31. Tinworth KD, Wynn PC, Boston RC et al. Evaluation of commercially available assays for the measurement of equine insulin. Domest Anim Endocrinol. 2011; 41, 81-90.

32. Ozanne SE, Nave BT, Wang CL et al. Poor fetal nutrition causes long-term changes in expression of insulin signalling components in adipocyctes. Am J Physiol. 1997; 273, E46E51.

33. Pratt SE, Geor RJ, McCutcheon LG. Repeatability of 2 methods of assessment of insulin sensitivity and glucose dynamics in horses. $J$ Vet Intern Med. 2005; 19, 883-888.

34. Gatford KL, De Blasio MJ, Thavaneswaran P et al. Postnatal ontogeny of glucose homeostasis and insulin action in sheep. Am J Physiol Enodocrinol Metab. 2004; 286, E1050-E1059.

35. Chamson-Reig A, Thyssen SM, Hill DJ, Arany E. Exposure of the pregnant rat to low protein diet causes impaired glucose homeostasis in the young adult offspring by different mechanisms in males and females. Exp Biol Med. 2009; 234, 1425-1436.

36. Brunton PJ, Sullivan KM, Kerrigan D, et al. Sex-specific effects of prenatal stress on glucose homoeostasis and peripheral metabolism in rats. J Endocrinol. 2013; 217, 161-173.

37. Hilawe EH, Yatsuya H, Kawaguchi L, Aoyama A. Difference by sex in the prevalence of diabetes mellitus, impaired fasting glycaemia and impaired glucose tolerance in sub-Saharan Africa: a systematic review and meta-analysis. Bull World Health Organ. 2013; 91, 671-682. 
38. Han R, Li A, Li L, Kitlinska JB, Zukowska Z. Material low-protein diet up-regulates the neuropeptide $\mathrm{Y}$ system in visceral fat and leads to abdominal obesity and glucose intolerance in a sex-and-time specific manner. FASEB J. 2012; 3528-3536.

39. Owens JA, Thavaneswaran P, De Blasio MJ, et al. Sex-specific effects of placental restriction on components of the metabolic syndrome in young adult sheep. Am J Physiol Endocrinol Metab. 2007; 292, E1879-E1889.

40. McKnight LL, Myrie SB, Mackay DS, Brunton JA, Bertolo RF. Glucose tolerance is affected by visceral adiposity and sex, but not birth weight, in Yucatan miniature pigs. Appl Physiol Nutr Metab. 2012; 37, 106-114.

41. Reaven EP, Curry DL, Reaven GM. Effect of age and sex on rat endocrine pancreas. Diabetes. 1987; 12, 1397-1400.

42. Galipeau DM, Yao L, McNeill JH. Relationship among hyperinsulinemia, insulin resistance and hypertension is dependent on sex. Am J Physiol Heart Circ Physiol. 2002; 283, H562-567.

43. Ruhe RC, Curry DL, Herrmann S, McDonald RB. Age and gender effects on insulin secretion and glucose sensitivity of the endocrine pancreas. Am J Physiol. 1992; 262, R671676.

44. Liu H, Schultz CG, De Blasio MJ, et al. Effect of placental restriction and neonatal exendin-4 treatment on postnatal growth, adult body composition and in vivo glucose metabolism in sheep. Am J Physiol Endocrinol Metab. 2015; 309, E589-E600.

45. Yki-Järvinen H. Sex and insulin sensitivity. Metabolism 1984; 33, 1011-1015.

46. Nagai K, Yoshida S, Konishi H Gender differences in the gene expression profiles of glucose transporter GLUT class I and SGLT in mouse tissues. Pharmazie. 2014; 69, 856-859. 
47. Langdown ML, Holness MJ, Sugden MC. Early growth retardation induced excessive exposure to glucocorticoids in utero selectively increases cardiac GLUT1 protein expression and Akt/protein kinase B activity in adulthood. J Endocrinol. 2001; 169, 11-22.

48. Jaquet D, Vidal H, Hankard R, Czernichow P, Levy-Marchal C. Impaired regulation of glucose transporter 4 gene expression in insulin resistance associated with in utero undernutrition. J Clin Endocrinol Metab. 2001; 86, 3266-3271.

49. Zheng S, Rollet M, Pan YX. Protein restriction during gestation alters histone modifications at the glucose transporter 4 (GLUT4) promotor region and induced GLUT4 expression in skeletal muscle of female rate offspring. J Nutr Biochem. 2012; 23, 1064-1071.

50. Rijnen KE, van der Kolk JH. Determination of reference range values indicative of glucose metabolism and insulin resistance by use of glucose clamp techniques in horses. $\mathrm{Am}$ J Vet Res. 2003; 64, 1260-1264.

51. Carter RA, McCutcheon LJ, George LA, et al. Effects of diet-induced weight gain on insulin sensitivity and plasma hormone and lipid concentrations in horses. Am J Vet Res. 2009; 10, 1250-1258.

52. Powell DM, Reddy SE, Sessions DR, Fitzgerald BP. Effect of short-term exercise training on insulin sensitivity in obese and lean mares. Equine Vet J. 2002; Suppl 34, 81-84.

53. Bamford MJ, Potter SJ, Harris PA, Bailey SR. Breed differences in insulin sensitivity and insulinemic responses to oral glucose in horses and ponies of moderate body condition score. Domest Anim Endocrinol. 2014; 47, 101-107.

54. Murphy D, Reid SWJ, Love S. The effect of age and diet on the oral glucose tolerance test in ponies. Equine Vet J. 1997; 29, 467-470.

55. Kelsey MM, Zeitler PS. Insulin resistance of puberty. Curr Diab Rep. 2016; 16, 64.

56. Guillaume D, Salazar-Ortiz J, Martin-Rosset W. Effects of nutrition anon mares' ovarian activity and equines' puberty. In Nutrition and feeding of the brood mare. 2006. pp 
315-339. Ed. Miraglia N \& Martin-Rosset W. Waginingen Academic Publishers, The Netherlands.

57. Poore KR, Fowden AL. Insulin sensitivity in juvenile and adult pigs of low and high birth weight. Diabetologia 2004; 47, 340-348.

58. Horton DM, Saint DA, Owens JA, Kind KL, Gatford KL. Spontaneous intrauterine growth restriction due to increased litter size in the guinea pig programmes postnatal growth, appetite and adult body composition. $J$ Dev Orig Health Dis. 2016; DOI: $10.1017 / \mathrm{S} 2040174416000295$.

59. Peugnet P, Wimel L, Duchamp G, et al. Enhanced or reduced fetal growth induced by embryo transfer into smalle or larger breeds alters post-natal growth and metabolism in preweaning horses. PLoS One 2014; 9, e102044.

60. Nyirenda MJ, Lindsay RS, Kenyon CJ, Burchell A, Seckl JR. Glucocorticoid exposure in late gestation permanently programs rat hepatic phosphoenolpyruvate carboxykinase and glucocorticoid receptor expression and causes glucose intolerance in adult offspring. J Clin Invest. 1998; 101, 2174-81.

61. Jellyman JK, Valenzuela OA, Fowden AL. Glucocorticoid programming of the hypothalamic-pituitary-adrenal axis and metabolic function: Animal studies from mouse to horse. J Anim Sci. 2015; 93, 3245-3260. 


\section{FIGURE LEGENDS}

Figure 1: Mean \pm SEM values of the increment in plasma glucose (A), area under in the glucose curve (AUCG, B), the increment in plasma insulin (C) and the area under the insulin curve (AUCI, D) in response to administration of glucose $(0.25 \mathrm{~g} / \mathrm{kg}$ ) in female (dark symbols and columns) and male horses (white symbols and columns) at 1 year and 2 years of age after neonatal treatment with either ACTH (stippled columns, triangular symbols) or saline (Sal, filled columns, circular symbols). * significant effect of sex (two-way ANOVA, $\mathrm{P}<0.02$ ). At 1 year: Saline, females $n=6$, males $n=4$; ACTH, females $n=5$, males $n=4$. At 2 years: Saline females $n=5$, males $n=4$; ACTH, females $n=5$, males $n=4$.

Figure 2: Mean \pm SEM values of $(A)$ the glucose infusion rate (GIR) and (B) insulin sensitivity during a hyperinsulinaemic-euglycaemic clamp in female (dark columns) and male horses (white columns) at 1 and 2 years of age after neonatal treatment with either ACTH (stippled columns) or saline (filled columns) * significant effect of sex (two-ANOVA, $\mathrm{P}<0.01$ ). At 1 year: Saline, females $n=2$, males $n=3$; ACTH, females $n=4$, males $n=4$. At 2 years: Saline, females $n=4$, males $n=4$; ACTH females $n=5$, males $n=4$.

Figure 3: Relative abundance of the insulin receptor (InsR) to $\beta$-actin in individual female (F) and male (M) 2 year old horses after neonatal treatment with ACTH or saline and the mean value for the ACTH treated group (black columns) expressed relative to the mean for the saline controls (white columns) for (A) liver, (B) soleus muscle, (C) semitendinosus muscle, (D) gastrocnemius muscle and (E) biceps muscle. * significantly different from value in saline treated group ( $\mathrm{P}<0.03$, two-way ANOVA).

Figure 4: Relationship between birth weight (BW) and (A) the area under the glucose curve (AUCG) in response to glucose administration $(0.25 \mathrm{~g} / \mathrm{kg}, \mathrm{AUCG}=982-13.0 \mathrm{BW}, \mathrm{n}=18, \mathrm{r}=$ $-0.487, \mathrm{P}=0.04$ ) and (B) insulin sensitivity (IS) measured using the hyperinsulinaemiceuglycaemic clamp in horses at 2 years of age (IS $=-159+15.6 \mathrm{BW}, \mathrm{n}=17, \mathrm{r}=0.658, \mathrm{P}=$ $0.0039)$. 
Figure 1

Year 1

A.

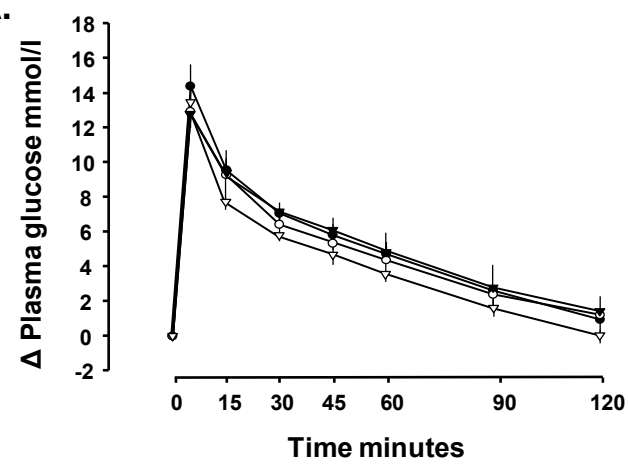

B.

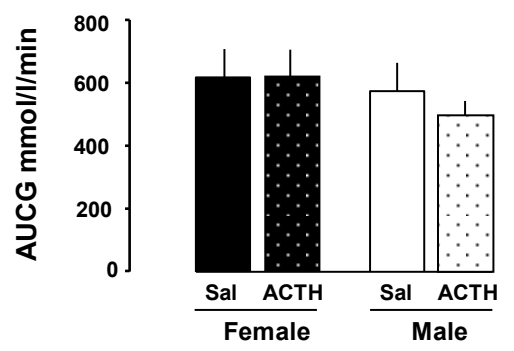

c.

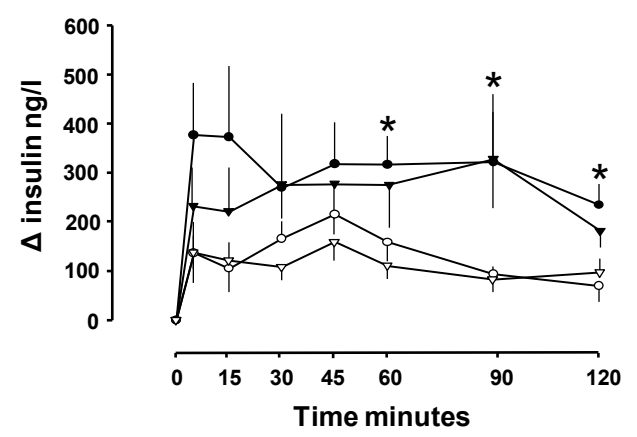

D.

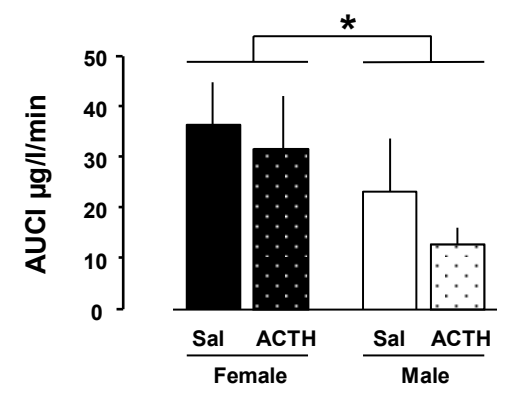

Year 2
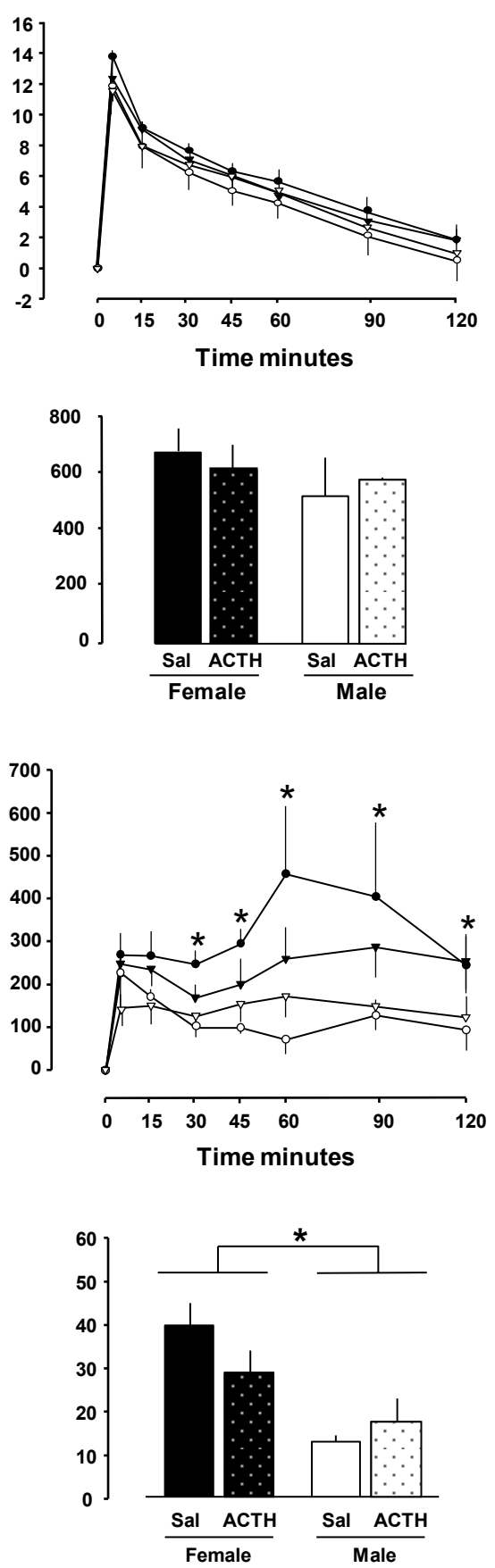
Figure 2

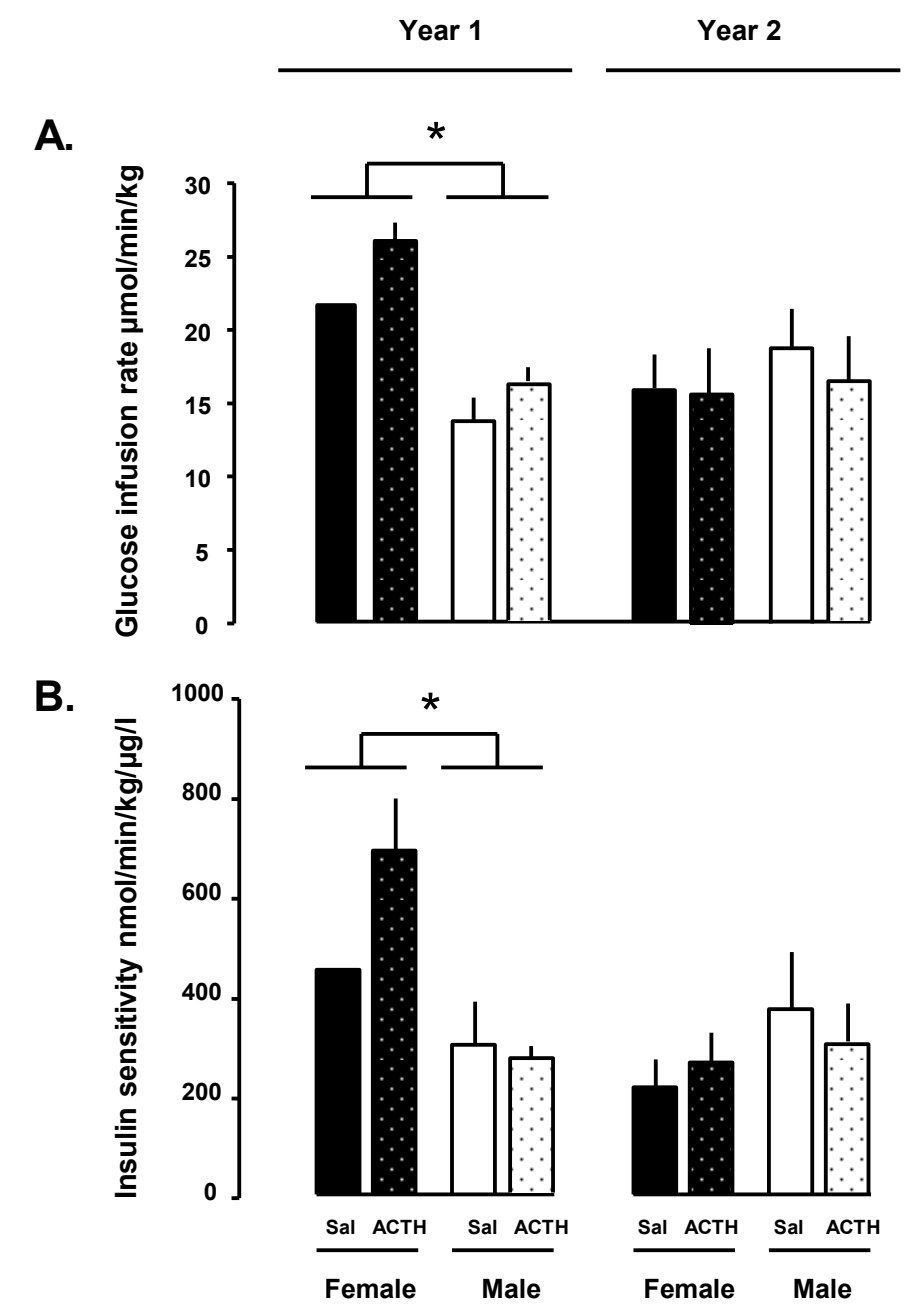


Figure 3

A. Liver
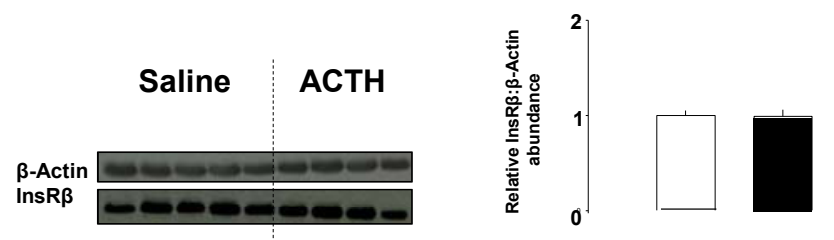

B. Soleus muscle

$\beta$-Actin
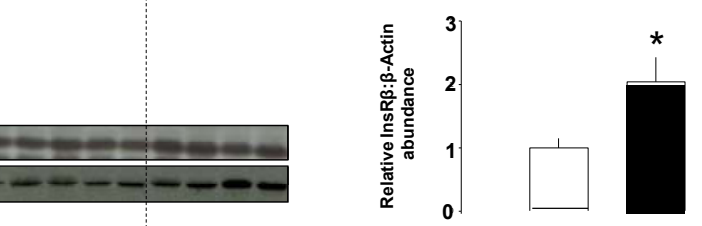

C. Semitendinosus muscle

D. Gastrocnemius muscle

$\beta$-Actin InsR $\beta$

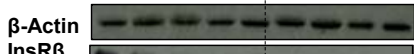
InsR $\beta$
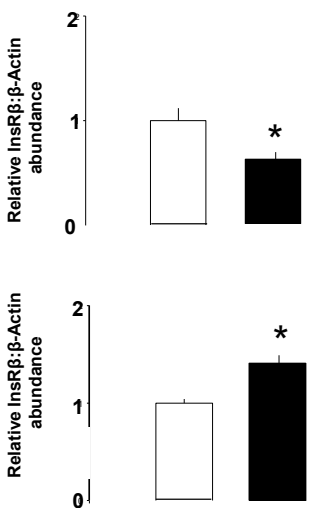

E. Biceps muscle

$$
\begin{aligned}
& \beta \text {-Actin } \\
& \text { InsR } \beta
\end{aligned}
$$
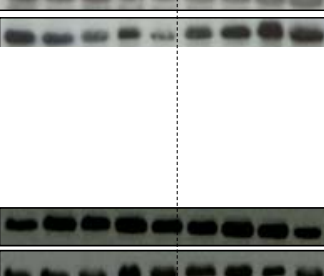

F F F M M F F M M

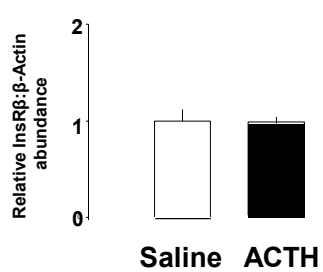


Figure 4

A.

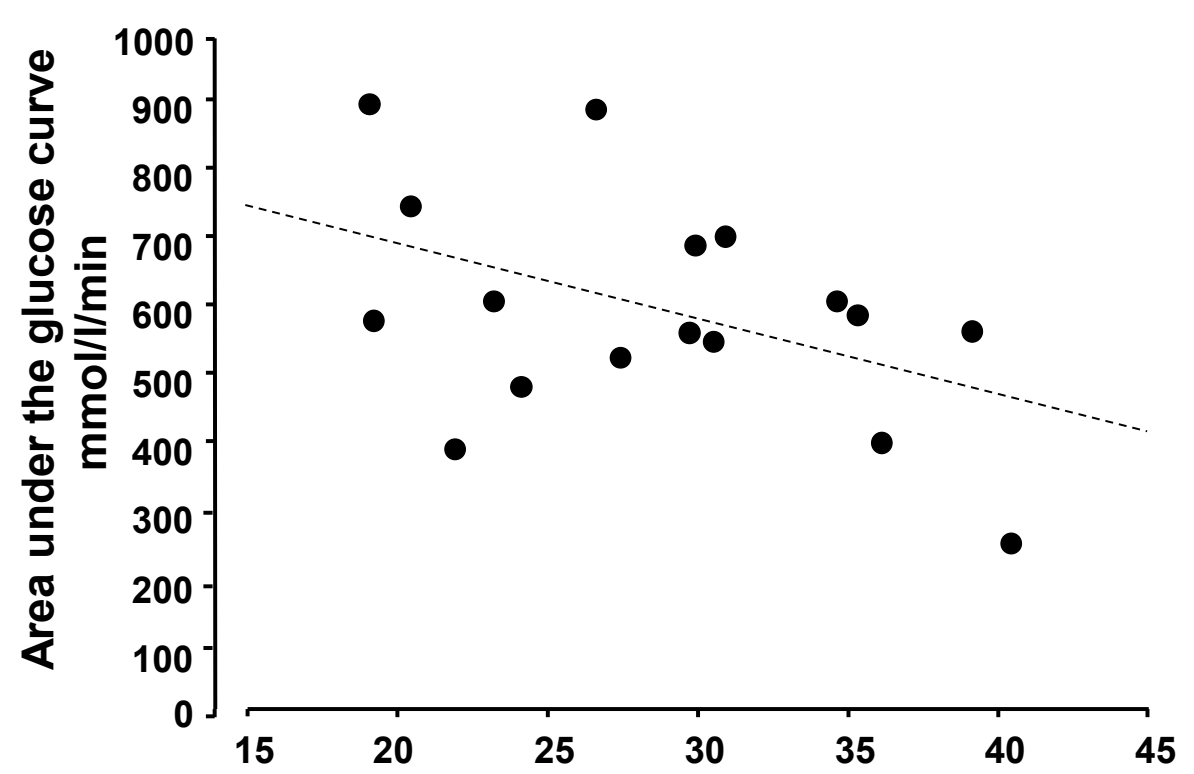

B.

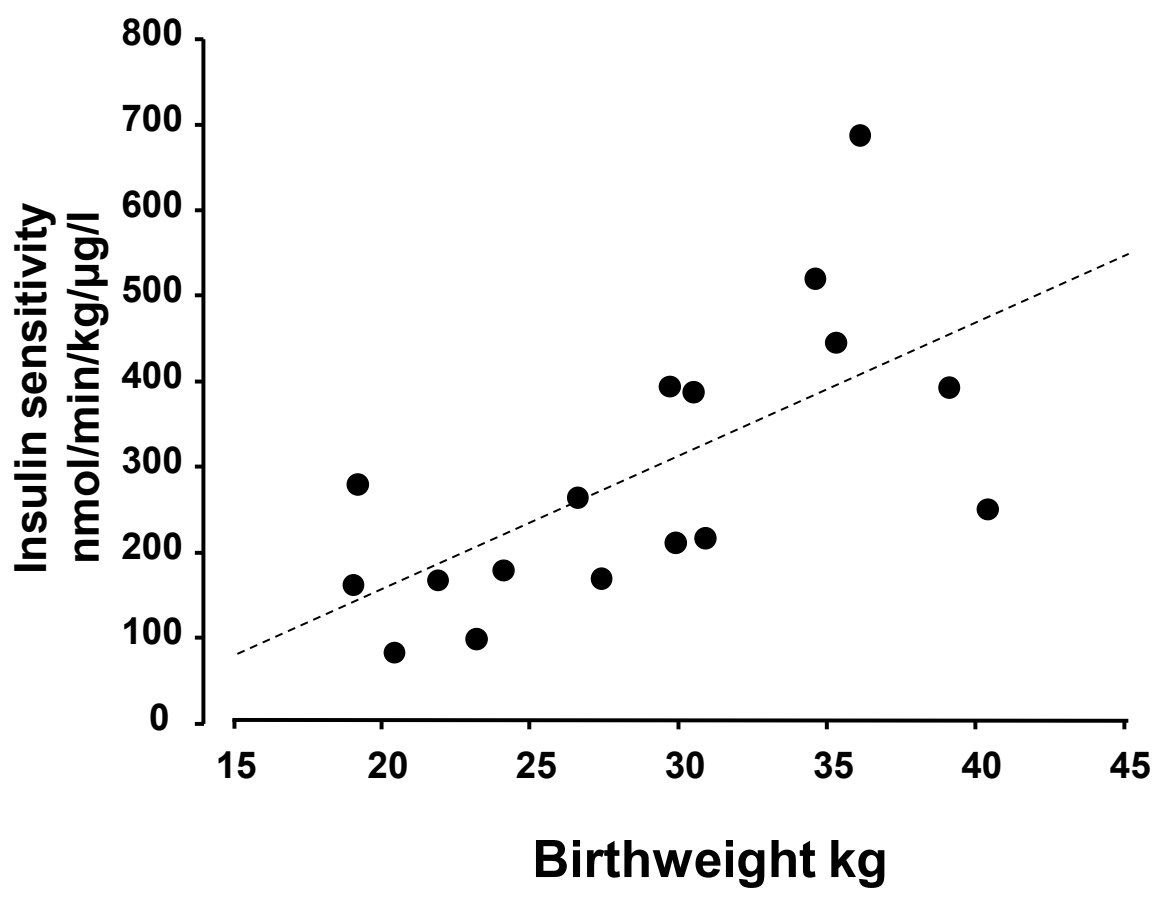

